PENENTUAN NASABAH PENERIMA REWARD PRODUK GOLD DENGAN METODE SIMPLE ADDITIVE WEIGHTING (SAW) STUDI KASUS : PT. PINJAM INDONESIA

Riki Ruli A. Siregar; Faizal Fachrurrozi

IMPLEMENTASI METODE BACKWARD CHAINING PADA DATA WAREHOUSE DAOP 1 JAKARTA PT. KAI (PERSERO) Rakhmat Arianto; Chandra Bagus Sugiarto

IMPLEMENTASI METODE DETEKSI TEPI CANNY PADA OBJEK SEBAGAI MODEL KEAMANAN APLIKASI PADA SMARTPHONE ANDROID

Abdul Haris; Andi Prasetyo

ANALISA DATA DAN PERANCANGAN APLIKASI SERVICE PELANGGAN PT. JNE UNTUK PENINGKATAN KUALITAS LAYANAN

Dewi Arianti Wulandari; Sonny Syahrindra Putra

JARINGAN AD-HOC VEHICULAR (VANET) : TINJAUAN TENTANG ARSITEKTUR, KARAKTERISTIK, APLIKASI, DAN PROTOKOL MEDIUMACCESS CONTROL (MAC)

Rosida Nur Aziza

PERANCANGAN APLIKASI PENJADWALAN MATA KULIAH MENGGUNAKAN METODE CONSTRAINT PROGRAMMING Syam Gunawan

RANCANGAN TATA KELOLA PEREMAJAAN RUANG KELAS DIREKTORAT PEMBINAAN SEKOLAH DASAR

Ratna Mutu Manikam; Purwanto

PENGEMBANGAN AMORIK MENGGUNAKAN METODE GARIS SINGGUNG TERHADAP DUA LINGKARAN DAN PERSAMAAN KURVA BEZIER ORDE DUA.

Darma Rusjidi

OPTIMALISASI PENGAMBILAN KEPUTUSAN PENILAIAN KINERJA DOSEN PADA PERGURUAN TINGGI ISLAM XYZ MENGGUNAKAN AHP (ANALYTICAL HIERARCHY PROCESS)

Rahma Farah Ningrum

PENGAMANAN SMS PADA TELEPON SELULER BERBASIS ANDROID MENGGUNAKAN ALGORITMA TRIPLE DES Raka Yusuf; $M$. Rival Suheri

APLIKASI LATIHAN SOAL UJIAN TEORI SURAT IZIN MENGEMUDI BERBASIS WEB Harni Kusniyati; Raka Yusuf; Andri Setiawan

RANCANG BANGUN SIMULASI TERJADINYA LISTRIK DENGAN SUMBER DAYA SAMPAH BERBASIS MULTIMEDIA (STUDI KASUS : TPST BANTAR GEBANG)

Yasni Djamain; Ika Fitriyani Putri

\begin{tabular}{|c|c|c|c|c|c|c|}
\hline \multirow{2}{*}{ 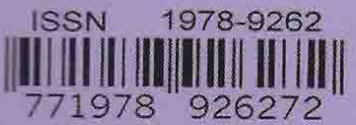 } & \multicolumn{6}{|c|}{ SEKOLAH TINGGI TEKNIK - PLN (STT-PLN) } \\
\hline & PETIR & VOL. 9 & NO. 1 & HAL. 1 - 87 & JAKARTA, MARET 2016 & ISSN $1978-9262$ \\
\hline
\end{tabular}




\title{
IMPLEMENTASI METODE DETEKSI TEPI CANNY PADA OBJEK SEBAGAI MODEL KEAMANAN APLIKASI PADA SMARTPHONE ANDROID
}

\author{
Abdul Haris; Andi Prasetyo \\ Sekolah Tinggi Teknik - PLN, Jakarta \\ kemasku@yahoo.com; andi_pras@yahoo.com
}

\begin{abstract}
ABSTRAK
Perkembangan teknologi mendorong sistem keamanan aplikasi pada smartphone android untuk mengembangkan salah satu fiturnya yaitu pengenalan objek. Pengenalan Objek adalah teknologi yang memungkinkan kita untuk mengidentifikasi atau memverifikasi objek melalui sebuah gambar digital dengan cara mencocokkan tekstur lekuk objek dengan data objek yang tersimpan di database. Misalnya mencocokkan wajah seperti lekuk hidung, mata dan dagu.

Terdapat beberapa metode untuk mendukung kerja dari pengenalan objek diantaranya yaitu deteksi tepi. Deteksi tepi dapat merepresentasikan objek-objek yang terkandung dalam citra bentuk dan ukurannya serta informasi tentang tekstur dari suatu objek. Salah satu metode pada deteksi tepi yang paling baik adalah deteksi tepi canny yang memiliki tingkat kesalahan yang minimum dibanding dengan metode deteksi tepi lain.

Deteksi tepi canny akan menghasilkan citra yang telah diolah menjadi citra baru. Citra baru tersebut akan disimpan pada basis data yang nantinya akan dicocokan pada citra objek baru yang digunakan sebagai teknik membuka aplikasi pada smartphone android.
\end{abstract}

Kata Kunci : Sistem keamanan aplikasi, Android, Citra, Pengenalan Objek, Deteksi Tepi Canny.

\section{ABSTRACT}

The development of technology push security system applications on android smartphone to develop one of its features that is detection of the object. The detection of Objects is a technology that allows us to identify or verify an object through a digital image by matching the texture of the object with the curve of the data objects stored in the database. For example, to match the curve of the face such as the nose, eyes and chin.

There are several methods to support the work of object detection among which edge detection. Edge detection can represent the objects contained in the image of the shape and size as well as information about the texture of an object. the best method of edge detection is canny edge detection which has the minimum error rate compared with other edge detection methods.

Canny edge detection will generate the image that has been processed into a new image. The new image will be stored on a database that will be matched to the image of a new object that is used as the opening applications on android smartphone.

Keyword : Security application system, Android, Image, Object detection, Canny Edge Detection

\section{Pendahuluan}

Teknologi dewasa ini telah berkembang sangat pesat. Segala peralatan dan fasilitas dari berbagai bidang di dunia kini telah memanfaatkan teknologi digital dengan tujuan untuk membantu memudahkan tugas atau pekerjaan manusia. Salah satu bidang yang kini telah memanfaatkan kemajuan teknologi adalah dalam bidang telekomunikasi, terutama pada perkembangan telepon genggam

Sebagai telepon pintar atau smartphone yang memiliki fitur canggih didalamnya, smartphone membutuhkan sistem operasi yang mendukung segala kemampuan canggih tersebut, adapun sistem operasi smartphone yang berkembang saat ini diantaranya adalah Android, los, Blackberry OS, Symbian dan Windows Phone. Namun masalah yang sering muncul dari kelima sistem operasi yang berkembang saat ini adalah masalah keamanan. Keamanan sangat dibutuhkan oleh masyarakat terutama pada masyarakat yang sangat menutamakan privasi pribadi. Sistem keamanan pada smartphone diutamakan untuk melindungi aplikasi penting didalamnya seperti mobile banking, sms banking, social media dan lain-lain sehingga smartphone membutuhkan pengamanan yang lebih.

Teknologi keamanan smartphone dengan pendeteksian objek sebenarnya telah diterapkan pada smartphone Android versi 4.0 Ice Cream Sandwich dengan pengenalan objek wajah/ face recognition. Namun terdapat banyak sekali kekurangan yang terdapat pada tekhnologi bawaan android tersebut seperti pengamanan face recognition tersebut hanya digunakan sebagai pengaman halaman utama (Home) saja dan bukan sebagai pengunci aplikasi tertentu yang diinginkan oleh pengguna. 
Metode Deteksi tepi juga tidak dikembangkan sebagai metode pengolahan citra pada penguncian aplikasi smartphone padahal metode deteksi tepi canny merupakan metode yang sudah banyak digunakan dalam pendeteksian seperti pendeteksian pola batik, pendeteksian pola sarung, pendeteksian uang palsu dan lain-lain. Metode detekasi tepi canny juga merupakan metode terbaik dibandingkan dengan ketiga metode lainnya yaitu metode deteksi tepi sobel, deteksi tepi Prewitt dan deteksi tepi robet.

\section{Landasan Teori}

\section{a. Android}

Andoid adalah sebuah sistem operasi untuk perangkat mobile berbasis Linux yang mencakup sistem operasi, middleware dan aplikasi. Android menyediakan platform tebuka bagi para pengembang untuk menciptakan aplikasi mereka. Awalnya, Google Inc. membeli Android Inc. yang merupakan pendatang baru yang membuat peranti lunak untuk smartphone. Kemudian untuk mengembangkan Android, dibentuklah Open Handset Alliance, konsorsium dari 34 perusahaan peranti keras, peranti lunak dan telekomunikasi, termasuk Google, HTC,Intel, Motorola, Qualcomm, T-Mobile dan Nvidia. (Safaat H. Nazruddin, 2014)

Pada saat perilisan perdana Andorid, 5 November 2007, Android bersama Open Handset Alliance menyatakan mendukung pengembangan open source pada perangkat mobile. Di lain pihak, Google merilis kode-kode Android di bawah lisensi Apache, sebuah lisensi perangkat lunak dan open platform perangkat seluler.

Sekitar September 2007 Google mengenalkan Nexus One, salah satu jenis smartphone yang menggunakan Android sebagai sistem operasinya.Telepon seluler ini diprodukasi oleh HTC Corporation dan tersedia di pasaran pada 5 Januari 2010. Pada 9 desember 2008, diumumkan anggota baru yang bergabung dalam program kerja Andoid ARM Holdings, Atheros Communications, diproduksi oleh Asustek Computer Inc, Garmin Ltd, Softbank, Sony Ericsson, Toshiba Corp dan Vodafone Group Plc. Seiring pembentukan Open Handset Alliance, $\mathrm{OHA}$ mengumumkan produk perdana mereka, Android, perangkat mobile yang merupakan modifikasi kernel Linux 2.6. Sejak Android dirilis telah dilakukan berbagai pembaharuan berupa perbaikan bug dan penambahan fitur baru.

Pada masa saat ini kebanyakan vendorvendor smartphone sudah memproduksi smartphone berbasis Android, vendor-vendor itu antara lain HTC, Motorola, Samsung, LG, HKC, Huawei, Archos, Dell, Nexus, Nexian, IMO dan masih banyak lagi vendor smartphone didunia yang memproduksi android. Hal ini karena android itu adalah sistem operasi yang open source sehingga bebas didistribusikan dan dipakai oleh vendor manapun. b. Deteksi Tepi Canny

Canny adalah algoritma deteksi tepi yang banyak digunakan dalam berbagai penelitian karena dinilai sebagai algoritma deteksi tepi yang paling optimal. Langkah awal pada algoritma Canny adalah mengimplementasikan tapis Gaussian pada citra untuk menghilangkan derau. Kemudian dilanjutkan dengan melakukan deteksi tepi pada citra dengan salah satu algoritma deteksi tepi yang ada, misalnya Sobel atau Prewitt.

Berikut adalah langkah-langkah dalam melakukan deteksi tepi Canny :

Langkah pertama adalah menghilangkan derau yang ada pada citra dengan menerapkan tapis Gaussian. Proses ini menghasilkan citra yang tampak sedikit buram. Hal ini dimaksudkan untuk mendapatkan tepian citra yang sebenarnya. Bila tidak dilakukan maka garis-garis lurus juga akan dideteksi sebagai tepian. Berikut ini adalah tapis Gaussian

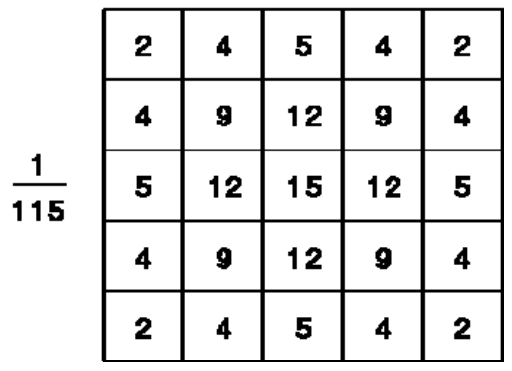

Gambar 2.1 Tapis Gaussian

Selanjutnya melakukan deteksi tepi dengan salah satu operator deteksi tepi (Operator Sobel dan Prewitt) dengan melakukan pencarian secara horizontal $\left(G_{x}\right)$ dan secara vertical $\left(G_{y}\right)$ melalui rumus

$$
\begin{aligned}
|G|=\mid G \quad & G x=\text { pencarian secara horizontal } \\
G y & =\text { pencarian secara vertikal }
\end{aligned}
$$

Operator Sobel yaitu sepasang kernel berupa matriks berukuran $3 \times 3$ untuk mendeteksi tepi vertical dan horizontal.
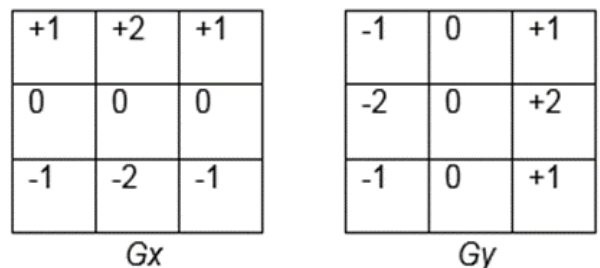

Gambar 2.2 Deteksi Tepi Vertikal dan Horisontal I

Prewitt merupakan algoritma deteksi tepi yang hampir serupa dengan Sobel, tetapi algoritma ini menggunakan Operator Prewitt yang nilainya agak berbeda dengan Operator Sobel. 

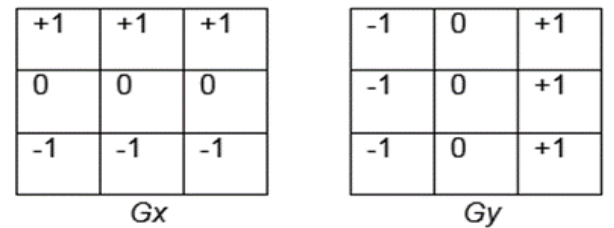

Gambar 2.3 Deteksi Tepi Vertikal dan Horisontal II

Untuk menghitung jarak gradient, digunakan persamaan berikut :

$|\mathrm{G}|=\sqrt{G x^{2}+G y^{2}}$ Persamaan Gradient 1

Kemudian untuk menghitung arah dari garis tepi yang dihasilkan, digunakan persamaan berikut :

$\theta=\arctan \left(\frac{G y}{G x}\right)$ Persamaan Gradient 2

Langkah berikutnya adalah membagi garisgaris yang ada menjadi 4 warna terpisah dengan sudut masing-masing dengan ketentuan yaitu :

1. Derajat 0 - 22,5 dan 157,5 - 180 berwarna kuning.

2. Derajat $22,5-67,5$ berwarna Hijau.

3. Derajat 67,5 - 157,5 berwarna Merah.

Kemudian memperkecil masing-masing garis tepi agar menjadi tipis (non maximum surpression). Langkah terakhir adalah melakukan proses binerisasi berdasarkan nilai low \& high threshold yang diberikan (Putra Darma,2010).

\section{c. Flowchart}

Diagram alir (flowchart) adalah bagan (chart) yang menunjukan alir (flow) di dalam program atau prosedur sistem secara logika. Diagram alir program (program flowchart) merupakan bagan alir yang mirip dengan bagan alir sistem, yaitu untuk menggambarkan prosedur di dalam sistem. (Jogiyanto, 2005).

\section{Metodologi Penelitian}

Pada bagian metodologi ini terdiri dari dua tahap yang pertama analisa masalah dan tahap kedua melakukan perancangan aplikasi. Berikut tahap-tahapnya :

\section{AnalisisMasalah}

Dalam analisa ini dari gambar yang di capture terlebih dahulu dikonversikan ke dalam bentuk matrik seperti pada Tahap awal ini dari gambar didapatkan lalu melakukan perubahan dan pengelompokan menjadi matrik seperti berikut :
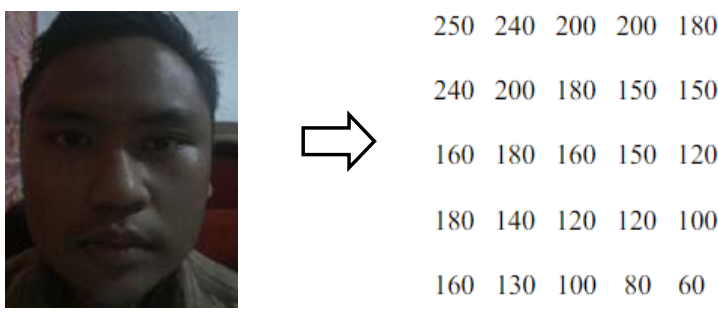

Kemudian seleksi matrik diatas menggunakan Gaussian yang menghasilkan matrik :

$\begin{array}{lcccl}179 & 171 & 143 & 143 & 129 \\ 171 & 143 & 129 & 107 & 107 \\ 114 & 129 & 114 & 107 & 86 \\ 129 & 100 & 86 & 86 & 71 \\ 114 & 93 & 71 & 57 & 43 \\ & \text { Kemudian } & \text { lakukan } & \text { seleksi } & \text { menggunakan }\end{array}$
salah satu tepian yaitu tepian prewit dengan matrik sebagai berikut:

$$
\begin{aligned}
& P_{x}=\left[\begin{array}{rrr}
-1 & 0 & 1 \\
-1 & 0 & 1 \\
-1 & 0 & 1
\end{array}\right] \\
& P_{y}=\left[\begin{array}{rrr}
1 & 1 & 1 \\
0 & 0 & 0 \\
-1 & -1 & -1
\end{array}\right]
\end{aligned}
$$

menemtukan seleksi horizontal dengan menggunakan $P_{X}$, diperoleh perhitungan :

$$
\begin{aligned}
\mathrm{G}_{1}(x, y) & =\mid(-1 * 143)+(-1 * 114)+(-1 * 100)+(1 * \\
107)+(1 & * 107)+(1 * 86) \mid \\
& =|(-57)| \\
& =57
\end{aligned}
$$

menentukan seleksi vertikal dengan menggunakan $\mathrm{P}_{\mathrm{y}}$, diperoleh perhitungan :

$$
\begin{aligned}
\mathrm{G}_{2}(x, y) & =\mid(-1 * 143)+(-1 * 129)+(-1 * 107)+(1 * \\
100)+(1 & * 86)+(1 * 86) \mid \\
& =|(-107)|=107 \\
\mathrm{G}(x, y) & =\left(\left|\mathrm{G}_{1}(x, y)\right|+\left|\mathrm{G}_{2}(x, y)\right|\right) \\
& =57+107=163 \\
\mathrm{G}(x, y) & =\max \left(\left|\mathrm{G}_{1}(x, y)\right|,\left|\mathrm{G}_{2}(x, y)\right|\right)=107 \\
\mathrm{G}(x, y) & =\left(\left|\mathrm{G}_{1}(x, y)\right|+\left|\mathrm{G}_{2}(x, y)\right|\right) / 2 \\
& =(163) / 2=81,5=82
\end{aligned}
$$

Langkah selanjutnya yaitu menentukan arah tepian dengan menggunakan acuan :

1. Semua arah tepi yang berkisar antara 0 dan 22,5 serta 157,5 dan 180 derajat (warna biru) diubah menjadi 0 derajat.

2. Semua arah tepi yang berkisar antara 22,5 dan 67,5 derajat (warna kuning) diubah menjadi 45 derajat.

3. Semua arah tepi yang berkisar antara 67,5 dan 112,5 derajat (warna merah) diubah menjadi 90 derajat.

4. Semua arah tepi yang berkisar antara 112,5 dan 157,5 derajat (warna hijau) diubah menjadi 135 derajat.

Berdasarkan acuan diatas maka dapat diketahui bahwa arah tepian pada citra yang telah dihitung diatas dengan nilai $\mathrm{G}(x, y)=82$ adalah 90 derajat begitu seterusnya hingga keseluruhan citra terdeteksi.

Langkah selanjutnya yaitu menetapkan fungsi nonmaximun suspension sehingga dihasilkan : 


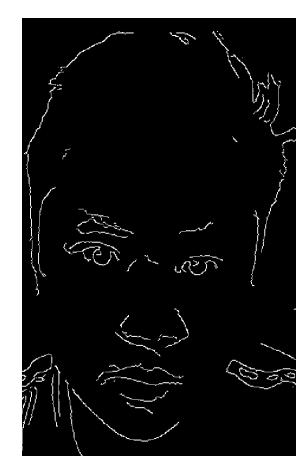

Setelah terbentuk citra deteksi tepi canny didapatkan maka dilakukan lagi mengidentifikasian matrik pada citra sehingga didapatkan :
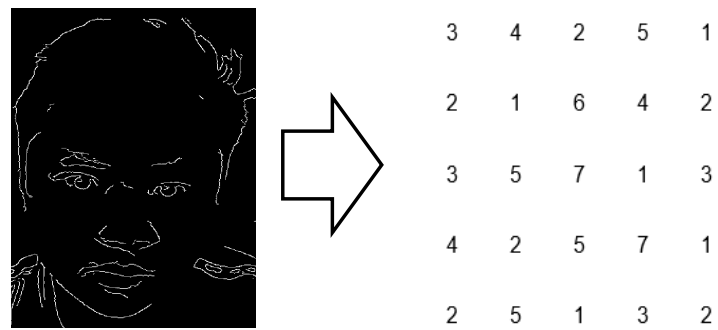

Kemudian lakukan seleksi menggunakan salah satu tepian yaitu tepian prewit dengan matrik sebagai berikut :

$$
\begin{aligned}
& P_{x}=\left[\begin{array}{rrr}
-1 & 0 & 1 \\
-1 & 0 & 1 \\
-1 & 0 & 1
\end{array}\right] \\
& P_{y}=\left[\begin{array}{rrr}
1 & 1 & 1 \\
0 & 0 & 0 \\
-1 & -1 & -1
\end{array}\right]
\end{aligned}
$$

Tentukan seleksi horizontal dengan menggunakan $P_{X}$, diperoleh perhitungan :

$\mathrm{G}_{1}(x, y)=\mid(-1$ * 3$)+(-1$ * 2$)+(-1$ * 3$)+(1$ * 2$)+(1$ * $6)+(1 * 7)$

$=|(7)|=7$

Tentukan seleksi vertikal dengan menggunakan $\mathrm{P}_{\mathrm{y}}$, diperoleh perhitungan :

$\mathrm{G}_{2}(x, y)=\mid(-1$ * 3$)+(-1$ * 4$)+(-1$ * 2$)+(1$ * 3$)+(1$ * $5)+(1 * 7) \mid$

$=|(6)|=6$

$\mathrm{G}(x, y)=\left(\left|\mathrm{G}_{1}(x, y)\right|+\left|\mathrm{G}_{2}(x, y)\right|\right)$

$=6+7=13$

$\mathrm{G}(x, y)=\max \left(\left|\mathrm{G}_{1}(x, y)\right|,\left|\mathrm{G}_{2}(x, y)\right|\right)=7$

$\mathrm{G}(x, y)=\left(\left|\mathrm{G}_{1}(x, y)\right|+\left|\mathrm{G}_{2}(x, y)\right|\right) / 2$

$=(6+7) / 2=6,5=7$

Sehingga didapat nilai curmax 13 dan curmin 7 .

\section{Perancangan}

Dalam perancangan diawali dengan membuat flowchart untuk menggambarkan proses bisnisnya seperti berikut :

\section{a. Diagram Flowchat}

Flowchart diawali dengan kondisi apakah pengguna yang sedang menggunakan aplikasi citra wajahnya terdaftar atau tidak. Jika pengguna tidak terdaftar maka pengguna diharuskan untuk mendaftarkan wajah untuk dijadikan training terlebih dahulu selanjutnya citra wajah tersebut disimpan ke database setelah tersimpan pengguna harus mengatur PIN kemudian setelah pin tersimpan pengguna harus memilih aplikasi yang akan dikunci oleh aplikasi "Facelock" setelah terpilih kemudian aplikasi tersebut akan tersimpan di database.

Jika pengguna yang menggunakan aplikasi merupakan pengguna terdaftar maka pengguna dapat langsung memilih aplikasi yang akan dibuka kemudian pengguna dapat menscan wajah dengan kamera. Setelah wajah di scan sistem akan mendeteksi citra wajah jika wajah terdeteksi sistem akan mencocokan citra wajah dengan training yang telah tersimpan di database, jika citra wajah dengan training cocok maka aplikasi akan terbuka namun jika tidak cocok maka akan diminta PIN untuk membuka aplikasi.

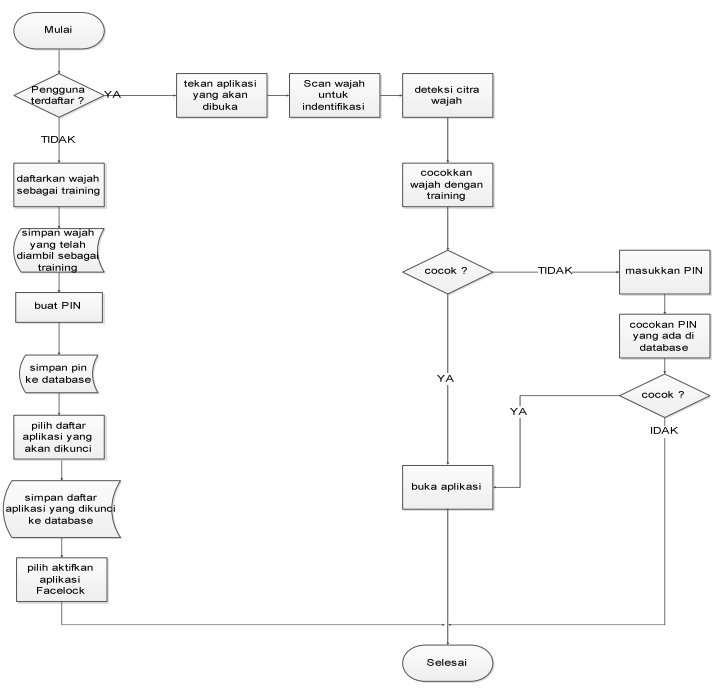

b. State Transition Diagram (STD)

State Transition Diagram adalah suatu diagram yang menggambarkan bagaimana suatu proses dihubungkan satu sama lain dalam waktu yang bersamaan. Sistem yang akan digunakan merumuskan rancangan State Transition Diagram sebagai berikut :

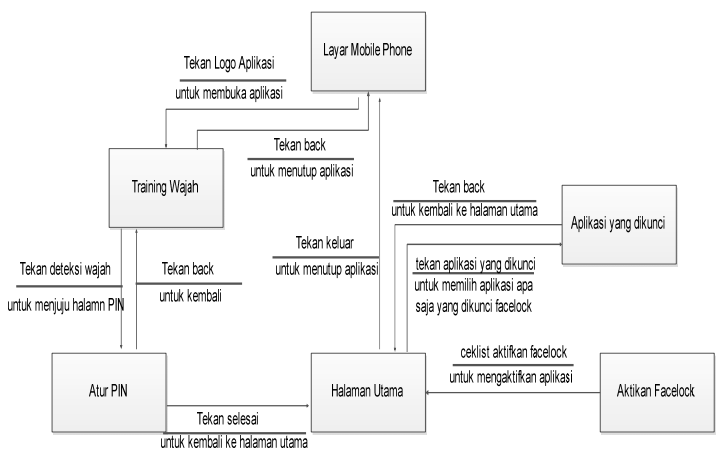

\section{Hasil dan Pembahasan}

Pada awal akan tampil halaman buat training wajah akan muncul setelah pengguna membuka 
aplikasi "Facelock". Sehingga tiap pengguna yang akan menggunakan aplikasi "Facelock" diharuskan untuk mentraining wajah terlebih dahulu. Halaman Buat Training wajah terdiri dari panel kamera untuk memindai wajah pengguna. Kemudian dibawah bagian kamera terdapat tombol "tambah deteksi wajah" dimana pengguna harus memindai wajah sebanyak 7 kali.

\section{FACELOCK}
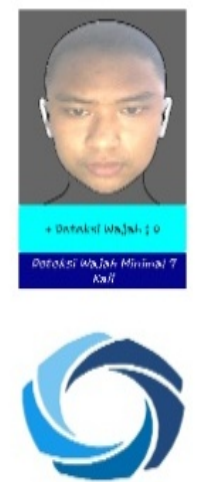

Halaman Buat PIN akan muncul setelah pengguna selesai melakukan training wajah setelah 7 kali melakukan training. Halaman PIN berfungsi untuk mengatur PIN yang digunakan jika aplikasi Facelock tidak dapat mendeteksi wajah. Halaman buat PIN terdiri dari nama aplikasi "Facelock" pada bagian atas layar kemudian di bawah nama aplikasi terdapat tulisan nama halaman yaitu "Atur PIN". Pada bagian tengah layar terdapat field input PIN dan Ulangi PIN kemudian tombol "Selesai". Setelah pengguna selesai melakukan training wajah dan mengatur pin maka pengguna akan masuk ke tampilan utama aplikasi. Halaman aplikasi utama memiliki dua pilihan yaitu pilihan "aktifkan aplikasi" yang berfungsi untuk mengaktifkan serta menonaktifkan aplikasi kemudian dibawah pilihan "aktifkan aplikasi" terdapat menu "Aplikasi yang dikunci" yang berfungsi untuk memilih aplikasi mana saja yang dilindungi oleh aplikasi facelock. Selanjutnya Menu "Aplikasi yg dikunci" berisikan daftar aplikasi yang terinstall pada perangkat android pengguna. Pada halaman ini pengguna dapat memilih aplikasi mana saja yang akan dilindungi oleh aplikasi
Facelock dengan cara menyentuh nama aplikasi yang tertera dan aplikasi akan otomatis terchecklist.

Pada halaman berikutnya akan muncul ketika pengguna akan membuka aplikasi yang telah dipilih sebelumnya oleh pengguna. Halaman ini terdiri dari tulisan nama aplikasi "Facelock" yang terletak di bagian atas layar kemudian pada bagian tengah layar terdapat panel kamera yang digunakan untuk memindai wajah. Jika wajah tidak berhasil dipindai maka secara otomatis akan muncul halaman masukkan PIN. Halaman ini berisi field input PIN dan tombol selesai.

\section{Kesimpulan dan Saran}

\section{Kesimpulan}

Berdasarkan pembahasan maka pada penelitian skripsi ini didapatkan beberapa kesimpulan dan saran, yaitu:

1. Pendeteksian Objek dapat dimanfaatkan sebagai metode alternatif untuk pengunci aplikasi pada smartphone Android.

2. Metode Deteksi Tepi Canny dapat digunakan sebagai metode yang dapat diterapkan untuk keamanan pada aplikasi smartphone Android.

\section{Saran}

Perihal saran-saran yang dapat dijadikan bahan pertimbangan untuk pengembangan pada aplikasi yang sama yang dapat berjalan di platform IOS, blackberry, dan Windowsphone.

\section{Daftar Pustaka}

Jogiyanto, 2005, "Analisis dan Desain Sistem Informasi : Pendekatan Terstruktur Teori dan Praktik Aplikasi Bisnis", Penerbit Andi : Yogyakarta

Pressman, Roger S. 2007. Rekayasa Perangkat Lunak: Pendekatan praktisi (Buku1). Martin, J. (1990). Information Engineering: Book II Planning and Analysis, PrenticeHall. Penerbit Andi : Yogyakarta.

Putra Darma, 2010, "Pengolahan Citra Digital", Penerbit Andi : Yogyakarta

Safaat H. Nazruddin. 2012. "Pemrograman aplikasi mobile smartphone dan tablet pc berbasis android", Penerbit Informatika : Bandung. 